\title{
SOBRE PEDRAS NO CAMINHO: ESTUDOS SOBRE ENSINO MÉDIO EM DOIS PERIÓDICOS DE EDUCAÇÃO ESPECIAL (2014 - 2016)
}

Mateus Henrique do Amaral amaralmateush@gmail.com Mestrando do PPGE da Universidade Metodista de Piracicaba

Tânia Valéria de Oliveira Scaranello valeriascaranello.psi@gmail.com Mestranda do PPGE da Universidade Metodista de Piracicaba

\section{Profa. Dra. Maria Inês Bacellar Monteiro}

monteirobim@gmail.com

Docente do PPGE da Universidade Metodista de Piracicaba 
RESUMO: Esse artigo é uma revisão de literatura de estudos que versam sobre o Ensino Médio, publicados na Revista Educação Especial (UFMS) e Revista Brasileira de Educação Especial entre 2014 e 2016. O objetivo é analisar como os artigos publicados, que tratam especificamente sobre a educação de alunos com deficiência, têm debatido essa etapa de ensino. Os textos foram selecionados a partir da leitura dos resumos publicados nos periódicos durante o período e, posteriormente, lidos integralmente, destacando-se o vínculo institucional dos autores, a necessidade educativa especial focalizada, temáticas, perspectivas teóricas e procedimentos metodológicos e os principais resultados/considerações de cada um. As considerações apontam para a necessidade de ampliação do debate sobre políticas públicas e a transversalidade da Educação Especial e o Ensino Médio, de modo a problematizar as novas reformas e buscar uma educação que forme jovens críticos e conscientes da realidade.

PALAVRAS-CHAVE: ensino médio, educação especia, revisão de literatura.

\section{ABOUT STONES ON THE WAY: STUDIES ABOUT HIGH SCHOOL ON TWO SPECIAL EDUCATION'S JOURNALS (2014-2016)}

ABSTRACT: This paper is a literature review of the studies focused on High school and Special Education published among 2014 and 2016 in two Brazilian academic journals: Revista Educação Especial and Revista Brasileira de Educação Especial. The aim is to analyze how these published texts have argued the High school and Special Education. The texts were selected by a reading of the abstracts published in the two journals during this period, and then read in full, highlighting the institutional link of the authors, the special educational need focused, thematic, theoretical perspectives and methodological procedures and the main results / considerations of each one. It has been concluded that it is necessary to broaden the debate on public policies and transversally of Special Education in basic education, as well as to problematize the new reforms of High School in Brazil.

KEYWORDS: high school, special education, literature review. 
No meio do caminho tinha uma pedra

Tinha uma pedra no meio do caminho

Tinha uma pedra

No meio do caminho tinha uma pedra

Carlos Drummond de Andrade

A seção Educação do jornal $O$ Globo publicou, no dia 29 de agosto de 2016, uma notícia intitulada Ensino médio é etapa que apresenta maior dificuldade na inclusão de deficiente $^{1}$. O texto discorre, sobretudo, acerca de uma pesquisa realizada pelo Instituto Unibanco, que teve como fonte a observação de microdados do Censo Escolar (INEP/MEC) referentes à inclusão dos alunos público-alvo da Educação Especial nas escolas de ensino básico, especialmente nos anos de 2007, 2011 e 2015.

Entre os dados divulgados no corpo da notícia, com base na pesquisa do Instituto Unibanco, encontram-se: 1. A progressiva queda no índice de alunos "incluídos" no sistema regular ao longo da trajetória escolar, culminando em um percentual de $0,8 \%$ frente aos 8 milhões de matrículas no Ensino Médio (E.M.), em 2015; 2. A falta de preparo das escolas com Ensino Médio e os entraves da configuração pedagógica dessa etapa de ensino; 3. O aumento do percentual de matrículas dos estudantes com deficiência em relação ao total de alunos no E.M. (de 0,2\% em 2007 para 0,8\% em 2015); 4. O percentual de $98 \%$ de alunos com deficiência no Ensino Médio matriculados nas escolas regulares (2015); e 5. O fato de o grande número de evasão ao longo da trajetória escolar não se restringir aos estudantes com deficiência, transtornos globais do desenvolvimento e altas habilidades/superdotação, mas as barreiras tenderem a ser maiores para este público.

A pesquisa do Instituto Unibanco apresenta, ainda, aquilo que denomina de "O Funil da inclusão", que ganha essa nomenclatura contraditória por estar relacionado com a progressiva evasão dos alunos público-alvo da Educação Especial das escolas regulares. A imagem 1, abaixo, elaborada no âmbito da pesquisa mencionada, apresenta dados em formato de gráficos sobre a matrícula e permanência desse conjunto de alunos no ensino regular.

1 Disponível em: <https://oglobo.globo.com/sociedade/educacao/ensino-medio-etapa-que-apresentamaior-dificuldade-na-inclusao-de-deficientes-20000762>. Acesso em 20 mai. 2017. 


\section{Imagem 01: Gráficos sobre Inclusão Escolar na Educação Básica, divulgados pela página do Instituto Unibanco.}

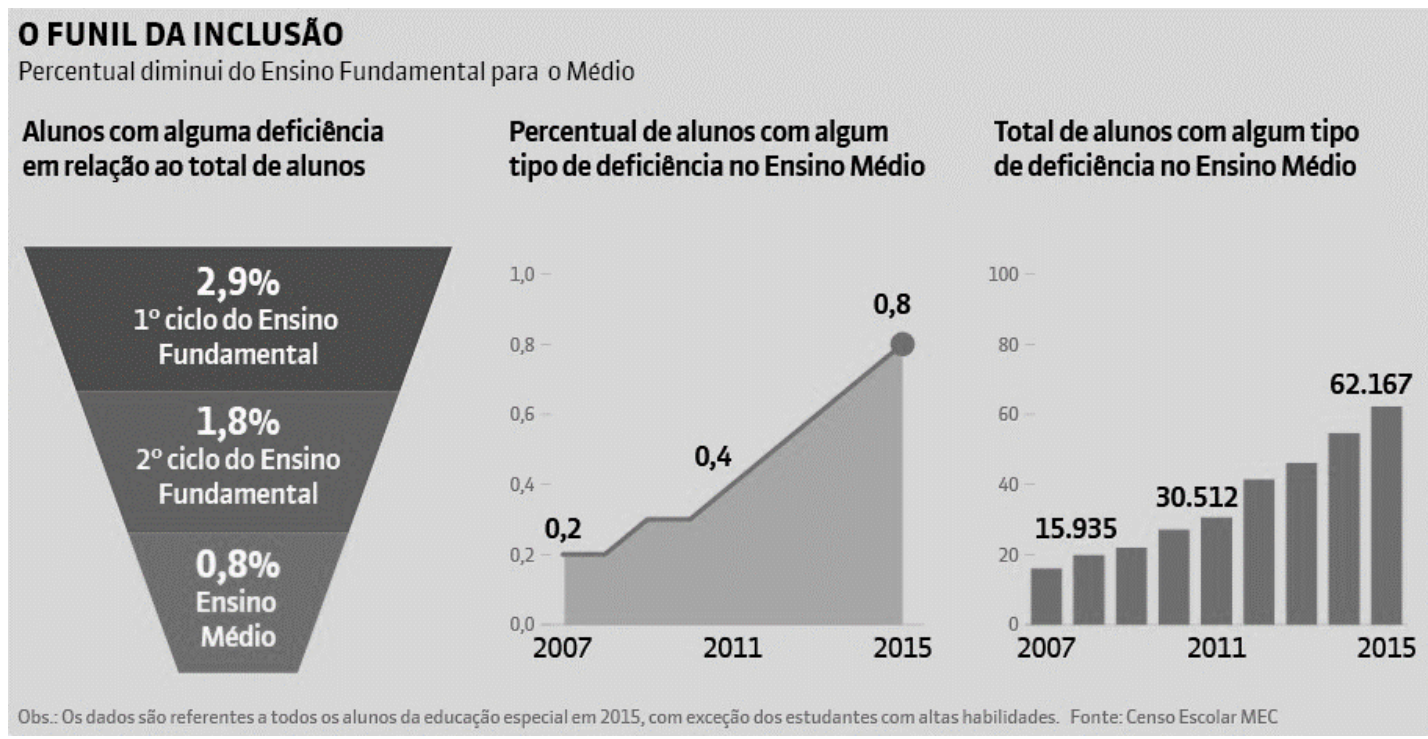

Disponível em: 〈http://www.institutounibanco.org.br/aprendizagem-em-foco/15/>.

Acesso em: 20 mai. 2017.

As informações presentes nos gráficos foram retiradas dos microdados do Censo

Escolar, divulgados entre os anos de 2007 e 2015, e apresentam números do alunado "da Educação Especial"2, exceto aqueles com altas habilidades/superdotação. É possível notar que, apesar do crescimento expressivo (quase $50 \mathrm{mil}$ ) das matrículas no Ensino Médio, a evasão de estudantes com deficiência revela-se - com base nesses dados - maior do que a de outros alunos, já que o percentual em relação ao total de matrículas é "afunilado" na última etapa da educação básica, passando de 2,9\% no Fundamental I para 0,8\% no Médio.

Outro dado sistematizado pelo Instituto Unibanco é que em relação ao total de matrículas desses alunos no Ensino Médio, aqueles com deficiência intelectual representam mais da metade (52\%), seguidos por alunos com deficiência física $(15,5 \%)$, baixa visão $(13,4 \%)$, deficiência auditiva $(8,3 \%)$ e surdez $(8,2 \%)$.

\footnotetext{
${ }^{2} \mathrm{O}$ documento Política Nacional de Educação Especial na Perspectiva da Educação Inclusiva (BRASIL, 2008) reconhece como estudantes público-alvo da Educação Especial os alunos com deficiência, transtornos globais do desenvolvimento e altas habilidades/superdotação. Nessa política, é considerado pessoa com deficiência aquela com impedimentos de longo prazo, de natureza física, mental ou sensorial, que frente às barreiras impostas socialmente fica restrita de uma participação plena nas diferentes esferas de atividade humana; com transtornos globais do desenvolvimento, aqueles que apresentam dificuldades e alterações no estabelecimento de relações interpessoais e, consequentemente, na comunicação e linguagem, incluindo-se nesse grupo os estudantes com autismo, síndromes do espectro do autismo e psicose infantil; e, por fim, com altas habilidades/superdotação, aqueles que demonstram potencial elevado, de modo isolado ou combinado, nas seguintes áreas: intelectual, acadêmica, liderança, psicomotricidade e artes, assim como grande criatividade, envolvimento na aprendizagem e realização de atividades de interesse (BRASIL, 2008).
} 
O texto do jornal $O$ Globo apresenta, também, opiniões de algumas pessoas. Ricardo Henriques, superintendente do Instituto Unibanco, atribui a realidade da evasão à complexidade da abordagem pedagógica no segundo segmento do Ensino Fundamental e Ensino Médio, que é fruto do grande número de disciplinas, e à "cultura da reprovação" instaurada nas escolas brasileiras, que retém os alunos com deficiência nas séries iniciais. Henriques entende que é necessário que haja uma escola com capacidade de acolher esse alunado, com organização que permita uma inclusão produtiva e alimente uma abordagem de alta expectativa para as pessoas com deficiência. Rodrigo Mendes, diretor executivo do Instituto "Rodrigo Mendes", que atua a favor da educação para os alunos com deficiência, atribui um importante papel ao Atendimento Educacional Especializado (AEE) no sentido de apoiar o professor e o estudante na eliminação de barreiras que existem na escola.

Estudos recentes que têm como base os microdados do Censo Escolar observam o fenômeno discutido pelo Instituto Unibanco, tais como Laplane (2014; 2016), Lima e Laplane (2016), Meletti e Ribeiro (2014) e Moreira e Carvalho (2014). Diferentemente de Henriques, entrevistado pelo $O$ Globo, que atribui essa realidade a fatores como a complexidade das etapas mais elevadas de ensino e à "cultura da reprovação", os estudos mencionados atribuem esse problema a questões mais relacionadas às dificuldades da escola em lidar com esse público. Ao analisar os microdados do Estado de São Paulo, Laplane (2016) aponta que a concentração de matrículas nos anos iniciais do Ensino Fundamental provavelmente evidencia as dificuldades da escola para lidar com as diferenças entre os modos de aprender, os tempos e a necessidade dos alunos. Meletti e Ribeiro (2014) enfatizam a (falta de) inserção dos alunos em processos efetivos de escolarização, ao indicar a defasagem idade/série em um grande número de estudantes com deficiência, que estuda com alunos até 12 anos mais novos, consequência tanto da retenção quanto da entrada tardia na escola. Segundo as autoras, essa realidade denuncia a precariedade da escolarização em um sistema que pretender ser inclusivo.

Moreira e Carvalho (2014) alertam para a escassez de trabalhos que remetem aos alunos com deficiência no Ensino Médio. Elas destacam que isso indica a invisibilidade desse alunado nessa etapa, assim como retrata “[...] não só o quadro de exclusão educacional desses alunos, mas a precariedade de políticas educacionais que contemplem estratégias de acesso e a permanência para a totalidade da educação básica” (p. 284). 
Frente a essa problemática envolvendo o Ensino Médio e a escolarização dos estudantes público-alvo da Educação Especial, isto é, frente às pedras no caminho que se colocam à progressão escolar desse alunado na educação básica, que culmina principalmente no "afunilamento" de matrículas, esse texto tem por objetivo analisar como os estudos publicados em duas revistas de grande circulação que tratam especificamente sobre a educação de alunos com deficiência, têm debatido essa etapa de ensino: a Revista Educação Especial (UFMS) e a Revista Brasileira de Educação Especial.

A escolha por esses dois veículos se deu por conta da representatividade que têm no campo da Educação Especial, configurando-se atualmente como espaços consagrados de divulgação científica na área. O recorte temporal feito $(2014$ - 2016) teve como marco inicial o ano de publicação do Plano Nacional de Educação - PNE (BRASIL, 2014), que entre as metas indica a universalização do ensino e atendimento educacional especializado ao público da Educação Especial, preferencialmente na rede regular de ensino, que garanta um sistema educacional inclusivo (Meta 4). Entre as estratégias, menciona o incentivo e fomento a pesquisas para o desenvolvimento de “[...] metodologias, materiais didáticos, equipamentos e recursos de tecnologia assistiva, com vistas à promoção do ensino e da aprendizagem, bem como das condições de acessibilidade dos (as) estudantes" (Estratégia 4.10).

\section{Procedimentos metodológicos: levantamento e seleção de artigos}

O levantamento dos artigos foi feito a partir do mapeamento de textos publicados nos periódicos de Educação Especial entre os anos de 2014 e 2016. Realizamos a leitura de resumos dos artigos disponibilizados nas páginas das revistas e posterior organização em tabelas, com as seguintes informações: edição publicada; nome do artigo; autor(es); vínculo institucional; necessidade educativa especial; etapa de ensino; procedimentos metodológicos; objetivos do artigo; perspectiva teórica; e principais resultados/considerações.

Os dados referentes a essas informações que não estão especificados pelos autores no resumo do texto foram identificados como "não especificado" e/ou "não identificado".

Após a organização das informações nas tabelas, selecionamos para ler integralmente aqueles que tratavam/tinham como foco específico o Ensino Médio. 


\section{Publicações da Revista Educação Especial (UFSM) e Revista Brasileira de Educação Especial por etapa de ensino (2014-2016)}

Antes de enfocar os dados levantados a partir da consulta dos resumos dos textos publicados, caracterizaremos brevemente os veículos de divulgação científica - Revista de Educação Especial (UFSM) e Revista Brasileira de Educação Especial -, tendo como principal base informações presentes nas páginas online das revistas.

A Revista Educação Especial é uma publicação editada pela Universidade Federal de Santa Maria (UFSM), localizada no estado do Rio Grande do Sul, e tem por objetivo veicular artigos inéditos na área de Educação Especial. A divulgação é feita quadrimestralmente, sendo três volumes anuais, que englobam os seguintes períodos: janeiro/abril, maio/agosto e setembro/dezembro. As duas primeiras edições atendem à demanda de fluxo contínuo e a terceira é organizada na forma de Dossiê Temático.

Durante o período consultado, os três números com dossiês temáticos tiveram como enfoque, respectivamente: Altas Habilidades/Superdotação (set./dez. 2014), com 14 artigos publicados sobre a temática e quatro em demanda contínua; Diferença, Educação e Cultura - Estudos Culturais/Pós-Estruturalistas (set./dez. 2015), com nove artigos sobre a temática e 11 em demanda contínua; e Itard e Victor - Educação Especial na contemporaneidade (set./dez. 2016), contendo nove artigos sobre o tema e outros nove em demanda contínua.

A Revista Brasileira de Educação Especial é uma publicação mantida pela Associação Brasileira de Pesquisadores em Educação Especial (ABPEE) ${ }^{3}$ e criada no ano de 1993, na cidade do Rio de Janeiro, durante a realização do III Seminário de Educação.

A publicação é trimestral e impressa atualmente na cidade de Marília (SP), em parceria com a Faculdade de Filosofia e Ciência da UNESP.

O quadro abaixo (quadro 1) traz os dados referentes às etapas de ensino focalizadas nos artigos, informação identificada a partir da leitura dos resumos. Organizamos esse conjunto de dados em cinco colunas, a primeira apresenta a etapa de ensino focalizada nos artigos, a segunda indica o número de textos encontrados na Revista Educação Especial (UFSM), a terceira indica o número de textos encontrados na Revista

\footnotetext{
${ }^{3}$ A Sede da ABPEE é móvel e acompanha a Diretoria eleita periodicamente. A sede atual é a Universidade Estadual de Londrina (UEL), na cidade de Londrina (PR).
} 
Brasileira de Educação Especial, a quarta apresenta o número total correspondente a cada etapa de ensino e a última coluna traz o percentual de cada etapa de ensino. A última linha da tabela apresenta o número total de artigos publicados entre 2014 e 2016 em cada uma das revistas e a soma geral.

Quadro 1 - Estudos publicados nos periódicos por etapa de ensino.

\begin{tabular}{|c|c|c|c|c|}
\hline Etapa de ensino & $\begin{array}{c}\text { REE }^{4} \\
\text { (UFSM) }\end{array}$ & RBEE $^{5}$ & Total & $\%$ \\
\hline Educação de Jovens e Adultos ${ }^{6}$ & 1 & 2 & 3 & $1 \%$ \\
\hline Ensino Básico & 16 & 20 & 36 & $13 \%$ \\
\hline Educação Infantil & 7 & 2 & 9 & $3 \%$ \\
\hline Educação Infantil/Ensino Fundamental & 1 & 1 & 2 & $1 \%$ \\
\hline $1^{\circ}$ Ciclo de Educação Básica ${ }^{7}$ & 2 & 0 & 2 & $1 \%$ \\
\hline Ensino Fundamental & 4 & 6 & 10 & $4 \%$ \\
\hline Ensino Fundamental I & 16 & 2 & 18 & $7 \%$ \\
\hline Ensino Fundamental II & 1 & 0 & 1 & $0 \%$ \\
\hline Ensino Fundamental/Ensino Médio & 2 & 0 & 2 & $1 \%$ \\
\hline Ensino Fundamental II/Ensino Médio & 1 & 0 & 1 & $0 \%$ \\
\hline Ensino Médio & 7 & 2 & 9 & $3 \%$ \\
\hline $\begin{array}{l}\text { Ensino Médio/Curso pré-vestibular/Ensino } \\
\text { Superior (Graduação e Pós-graduação) }\end{array}$ & 1 & 0 & 1 & $0 \%$ \\
\hline Educação profissional técnica de nível médio & 1 & 0 & 1 & $0 \%$ \\
\hline Ensino Superior & 15 & 10 & 25 & $9 \%$ \\
\hline Não especificado/identificado & 81 & 75 & 156 & $57 \%$ \\
\hline Total & 156 & 120 & 276 & $100 \%$ \\
\hline
\end{tabular}

Fonte: Elaboração própria a partir do levantamento bibliográfico realizado.

Durante os três últimos anos, foram publicados 156 artigos na Revista Educação Especial (UFSM) e 120 na Revista Brasileira de Educação Especial, o que constitui o total de 276 publicações. Nesse período, o número de textos publicados anualmente na REE (UFSM) variaram de um ano para o outro, sendo 51 textos em 2014, 53 em 2015 e 52 em 2016. Enquanto isso, a Revista Brasileira de Educação Especial manteve a mesma quantia de publicações anuais (40), divulgando exatamente dez estudos por edição ${ }^{8}$.

\footnotetext{
${ }^{4}$ A Sede da ABPEE é móvel e acompanha a Diretoria eleita periodicamente. A sede atual é a Universidade Estadual de Londrina (UEL), na cidade de Londrina (PR).

${ }^{5}$ Sigla para Revista Brasileira de Educação Especial.

${ }^{6}$ Sabemos que a Educação de Jovens e Adultos (EJA), na realidade, é identificada como uma modalidade de ensino, e não uma etapa, assim como são caracterizadas a Educação Infantil, Ensino Fundamental (subdividido em I e II), Ensino Médio, Ensino Técnico e Ensino Superior. Contudo, como o resumo dos artigos não especificam qual etapa do EJA abordam, optamos por manter como um dado a parte.

${ }^{7}$ Os estudos que têm a etapa de ensino identificada como " $1^{\circ}$ Ciclo de Ensino Básico" correspondem a trabalhos de pesquisadores portugueses, que enfocam o $1^{\circ}$ Ciclo da Educação Básica em Portugal. Em nosso texto, com o intuito de preservar a identidade e organização do ensino nos dois países (Brasil e Portugal), optamos por manter a nomenclatura portuguesa como um dado distinto.

${ }^{8}$ As resenhas publicadas no período foram desconsideradas em nosso levantamento, já que não se configuram como estudos inéditos. Durante o conjunto de anos enfocado, publicou-se três resenhas na RBEE: "Educação especial em Sergipe", por Iranilde dos Santos Rocha, presente no volume 20, n. 4, out./dez. 2014; "Futebol para Deficientes Visuais: Football 5-A-SIDE", com autoria de Gustavo Levandoski, publicado no volume 21, n. 1, jan./mar. 2015; e, por último, "Inclusão Escolar e os Desafios para a Formação de Professores", assinado por Tereza Cristina de Carvalho, no volume 22, n. 2, abr.jun. 2016.
} 


\section{Ensino Médio em foco nos periódicos brasileiros de Educação Especial}

O número de artigos que tem como foco específico o Ensino Médio representa apenas 3\% dos textos divulgados no período analisado. Assim, optamos por realizar a leitura integral dessas produções e distribuímos a discussão em tópicos que enfocam questões específicas: vínculo institucional do(s) autore(s); necessidade educativa especial; temática; perspectiva teórica e procedimento metodológicos utilizados; e principais resultados/considerações.

É interessante destacar que uma grande parcela dos textos foi elaborada em duplas (oito). No período estudado, a pesquisadora Renata Cardoso de Sá Ribeiro Razuck (Universidade de Brasília), publicou dois artigos que versam sobre o Ensino Médio, ambos na Revista Educação Especial (UFSM), os quais abordam o ensino de química para cegos.

Cinco textos foram publicados no ano de 2014, apenas um em 2015 e três em 2016.

\subsection{Vínculo institucional do(s) autor(es)}

Os nove artigos foram produzidos por dezenove autores diferentes, vinculados a onze universidades e uma rede municipal de ensino, todas localizadas no Brasil. Esse total está concentrado em três regiões do país, sendo Sul (cinco universidades/uma rede de ensino), Sudeste (três universidades) e Centro-Oeste (duas universidades). Entre os textos, não encontramos autor(es) vinculado(s) a instituições do Norte e Nordeste.

Os autores e instituições da região Sul estão distribuídos em dois estados: oito autores de cinco universidades e uma rede municipal de ensino do Paraná (Universidade Federal do Paraná, Universidade Tecnológica do Paraná, Universidade Estadual de Maringá, Universidade Estadual do Centro-Oeste, Faculdade Estadual de Paranaguá e Rede Municipal de Curitiba); e dois autores de uma universidade do Rio Grande do Sul (Centro Universitário Univates). Já na região Sudeste, encontramos: no Rio de Janeiro, dois pesquisadores vinculados à Universidade Federal Fluminense; e dois pesquisadores de duas universidades localizadas no estado de São Paulo (Universidade Estadual Paulista Júlio de Mesquita Filho e Universidade São Francisco). Por fim, na região Centro-Oeste, há três pesquisadores vinculados à Universidade de Brasília, localizada no Distrito Federal, e dois vinculados à Universidade Federal de Mato Grosso do Sul, no estado do Mato Grosso do Sul. 


\subsection{Necessidades educativas especiais}

Três estudos abordam a cegueira, três a surdez, dois não especificam um público e um enfoca a cegueira e a baixa visão. Um dado curioso é que entre os artigos que versam sobre a cegueira (4), três abordam o ensino de química para esses estudantes, o que discutiremos com maior profundida no próximo tópico (temáticas). Outra questão a ser observada é a limitação do público focalizado nos estudos, centrado sobretudo na cegueira e surdez. A deficiência intelectual, por exemplo, que representa atualmente o maior percentual de alunos "da Educação Especial” no Ensino Médio (52\%), não aparece focalizada nesses artigos.

\subsection{Temáticas}

Como já adiantamos no tópico anterior, uma parcela significativa dos estudos encontrados trabalha com o ensino-aprendizagem na disciplina de química para estudantes cegos, sendo um deles com foco para alunos com baixa visão também. Razuck e Guimarães (2014) elaboram materiais para formação inicial de professores em conjunto com alunos cegos. Ao trabalhar com protótipos de Modelos Atômicos, a ideia do texto é propor uma discussão sobre a importância de aplicação de recursos pedagógicos alternativos. Razuck e Oliveira Neto (2015) objetivam a elaboração de kits de modelos moleculares texturizados, visando estimular o aprendizado de todos (estudantes videntes, com baixa visão e cegos). Já Marchi e Silva (2016), apresentam um recorte de uma dissertação de Mestrado intitulada Deficiente visual: ensinando e aprendendo química através das tecnologias assistivas no ensino médio ${ }^{9}$. No artigo, é empreendido um estudo de caso, no contexto de formação continuada de professores, que aborda o uso de tecnologias assistivas para estudantes cegos. Por meio de observação em duas escolas estaduais, os autores analisam as práticas e anseios dos docentes e as necessidades dos alunos na sala de aula regular.

Andrade e Freitas (2016) também tem como foco a cegueira, investigando os indícios das possibilidades de aprender de um aluno cego matriculado no $2^{\circ}$ ano do Ensino Médio, nos momentos de aula de Educação Física na escola regular.

Frizzarini e Nogueira (2014) discutem o conhecimento dos alunos surdos fluentes em língua de sinais referentes à linguagem algébrica, que devido à sua característica abstrata é de difícil interpretação para uma língua viso-motora. O intuito é desenvolver

\footnotetext{
${ }^{9}$ A dissertação de Tânia Nússia da Costa Silva (2014) pode ser encontrada na Biblioteca Digital do Centro Universitário Univates: 〈https://www.univates.br/bdu/handle/10737/1066〉. Acesso em: 25 mai. 2017.
} 
uma avaliação diagnóstica dos principais registros de representação semiótica e suas coordenações possíveis no ensino e aprendizagem da álgebra para surdos fluentes em LIBRAS.

Mallman, Conto, Bagarollo e França (2014) atentam às contradições entre as políticas de inclusão e as situações vivenciadas cotidianamente nas escolas brasileiras, problematizando o modo que os profissionais do Ensino Médio, no interior do estado do Paraná, estão atuando com os alunos surdos. O objetivo é investigar as práticas pedagógicas nessa etapa de ensino, quando se tem em sala de aula um surdo.

Vargas e Gobara (2014) apontam o interesse em investigar o ensino e aprendizagem de Física no âmbito das escolas regulares. O objetivo é analisar o contexto das escolas de Campo Grande (MS) que recebem surdos e o apoio que estes precisam para fazer parte de uma escola que ofereça condições de ensino e respeite suas características.

O artigo de Moreira e Carvalho (2014) destaca a escassez de pesquisas relacionadas aos alunos com deficiência no Ensino Médio e o número desses jovens com idade escolar para frequentar essa etapa que evadem. $O$ intuito é discorrer sobre a (des)continuidade na trajetória do Ensino Fundamental ao Ensino Médio, atentando-se aos períodos de evasão acentuada.

Leme e Costa (2016) problematizam as influências e desdobramentos dos ordenamentos políticos na prática escolar, sobretudo a Declaração Universal dos Direitos Humanos (1946) e Constituição Federal (1988). O foco do texto é analisar a inclusão na perspectiva crítica, que demanda a participação coletiva com vistas à superação das barreiras que obstam a afirmação do direito à educação.

\subsection{Perspectiva teórica e procedimentos metodológicos}

Entre os artigos, apenas dois não explicitam e/ou especificam uma fundamentação teórica, que é o caso dos estudos de Moreira e Carvalho (2014) e Marchi e Silva (2016). Os outros indicam que se embasam na perspectiva histórico-cultural e nas ideias de Lev Vigotski (quatro), no marxismo (um), na semiótica e ideias de Raymond Duval (um) e na Teoria Crítica, de Theodor Adorno (um).

No artigo de Moreira e Carvalho (2014), os microdados do Censo Escolar MEC/INEP divulgados nos anos de 2007, 2008 e 2010 são analisados, buscando 
identificar alguns focos de evasão dos alunos com deficiência na trajetória escolar da educação básica. Para isso, as autoras olham para o número de matrículas totais e as específicas dos alunos com deficiência e elaboram cinco diferentes grupos: Grupo 1, que confronta o número de matrículas na $1^{\mathrm{a}}$ série $/ 2^{\circ}$ ano em $2007 \mathrm{com}$ a $4^{\mathrm{a}}$ série $/ 5^{\circ}$ ano em 2010, buscando identificar aqueles alunos que conseguiram chegar ao último ano do Ensino Fundamental I em tempo adequado; Grupo 2, que confronta as matrículas na $4^{\mathrm{a}}$ série $/ 5^{\circ}$ ano em 2007 com a $5^{\mathrm{a}}$ série $/ 6^{\circ}$ ano em 2008 , a fim de visualizar o acesso à segunda etapa do Ensino Fundamental; Grupo 3, que confronta as matrículas na $5^{\mathrm{a}}$ série $/ 6^{\mathrm{o}}$ ano de 2007 com as matrículas na $8^{\mathrm{a}}$ série $/ 9^{\circ}$ ano em 2010 , olhando a permanência na segunda etapa do Ensino Fundamental; Grupo 4, que apresenta a comparação entre o número de matrículas na $8^{\mathrm{a}}$ série $/ 9^{\circ}$ ano de 2007 com o $1^{\circ}$ ano do Ensino Médio de 2008, com o intuito de identificar o acesso à última etapa da educação básica; e, por fim, Grupo 5, que confronta as matrículas no $1^{\circ}$ ano do E.M. de 2008 com as matrículas no $3^{\circ}$ ano do E.M. em 2010, olhando a continuidade nessa etapa de ensino.

Marchi e Silva (2016) também não especificam a fundamentação teórica. Metodologicamente, as autoras destacam que se embasam na técnica de observação discutida por Oliveira $\left(2010^{10}\right.$ apud MARCHI \& SILVA, 2016), autora que identifica esta técnica como o instrumento que mais traz detalhes, que possibilita olhar o comportamento dos participantes do estudo e descobrir aspectos novos do contexto. O texto apresenta um estudo de caso, realizado na formação continuada de dois professores que ministram a disciplina de química e dois professores auxiliares, todos trabalham em escolas estaduais em que estudam alunos cegos. Foram realizadas observações, anotações por parte dos pesquisadores e aplicado um questionário, no qual os participantes apontavam as contribuições do curso.

Razuck e Guimarães (2014), discutindo o ensino de Modelos Atômicos para cegos, trazem algumas noções de Vygotsky ao pensar nas vias alternativas de desenvolvimento. Durante o estudo, contudo, as autoras se embasam em autores da perspectiva construtivista, quando citam Campos, Sá e Silva (2007 ${ }^{11}$ apud RAZUCK \& GUIMARÃES, 2014). É realizado um estudo de caso, que descreve a elaboração de

\footnotetext{
${ }^{10}$ OLIVEIRA, A. A. de. Observação e entrevista em pesquisa qualitativa. Revista Científica da Faculdade Cenecista de Vila Velha/FACEVV. v. 2, n. 4, (jan./jun. 2010). Vila Velha: FACEVV, 2010.

${ }^{11}$ CAMPOS, I. M.; SÁ, E. D.; SILVA, M. B. C. Atendimento Educacional Especializado - Formação Continuada a Distância de Professores para o Atendimento Educacional Especializado. Deficiência Visual. SEESP / SEED / MEC. Brasília. 2007.
} 
protótipos de Modelos Atômicos e o uso do material com um aluno cego, matriculado no segundo ano do Ensino Médio de uma escola pública do Distrito Federal. As interações com o aluno são analisadas à luz da perspectiva interativa/dialógica, mais especificamente a partir das ideias de Amaral e Montimer (2006 ${ }^{12}$ apud RAZUCK \& GUIMARÃES, 2014).

Os outros três estudos que apontam o embasamento teórico nas ideias de Vygotsky e na perspectiva histórico-cultural são os de Vargas e Gobara (2014), Razuck e Oliveira Neto (2015) e Andrade e Freitas (2016). O primeiro deles, a partir de um estudo de caso, investiga as interações que acontecem com alunos surdos matriculados em dez diferentes escolas estaduais de Campo Grande (MS) durante aulas da disciplina Física. Participaram do estudo 10 professores, 13 intérpretes de língua de sinais e 24 alunos surdos, que foram observados e entrevistados. Os dados foram analisados a partir da Análise de Conteúdo Categorial, discutida por Bardin (2009 ${ }^{13}$ apud VARGAS \& GOBARA, 2014). Razuck e Oliveira Neto (2015) discutem o trabalho com a química orgânica, descrevem a elaboração de kit de modelagem molecular e a avaliação do material, por meio de entrevistas com alunos cegos e com baixa visão matriculados no terceiro ano do Ensino Médio, realizadas em encontros na Sala de Recursos. Já no texto de Andrade e Freitas (2016), é apresentado o recorte de uma dissertação de mestrado, focalizando episódios vividos por um estudante cego matriculado no segundo ano, durante um semestre letivo nas aulas de Educação Física. O recurso utilizado para levantamento dos dados foi a videogravação e, em consonância com a perspectiva teórica adotada, os dados foram transcritos e analisados a partir da abordagem microgenética, discutida por Goés $\left(2000^{14}\right.$ apud ANDRADE \& FREITAS, 2016).

Mallmann, Conto, Bagarollo e França (2014) realizam um estudo de caso, com embasamento teórico na dialética marxista. O material empírico foi coletado por meio de audiogravação de entrevistas não estruturadas, realizadas individualmente com duas professoras (matemática e sociologia), duas pedagogas e uma intérprete de LIBRAS, que atuam com três surdos em uma escola estadual de um munícipio de médio porte do Paraná.

\footnotetext{
${ }^{12}$ AMARAL, E. M. R.; MORTIMER, E. F. Uma metodologia para análise da dinâmica entre zonas de um perfil conceitual no discurso da sala de aula. In: SANTOS, F. M. T.; GRECA, I. M. (Org.). A pesquisa em ensino de ciências no Brasil e suas metodologias. 1 ed. Ijuí (RS): Editora Unijuí, 2006, p. 239-296.

${ }^{13}$ BARDIN, L. Análise de Conteúdo. - 4 ed. rev. atual. - Lisboa: Edições 70, 2009.

${ }^{14}$ GÓES, M. C. R. de. A abordagem microgenética na matriz histórico-cultural: Uma perspectiva para o estudo da Constituição da Subjetividade. Caderno Cedes, ano 20, n. 50, p. 21, 2000.
} 
Frizzarini e Nogueira (2014) também enfocam a surdez. Fundamentados nas ideias de Raymond Duval, os autores aplicam uma avaliação diagnóstica dos diferentes registros de representação semiótica por sete alunos surdos fluentes em LIBRAS, matriculados no primeiro ano de uma Escola Especial localizada no interior de uma universidade situada em um município ao Norte do Paraná. As atividades foram aplicadas em quatro aulas e filmadas com o auxílio de duas câmeras (uma destinada à professora que traduzia, interpretava e respondia aos questionamentos e outra para os alunos surdos).

Por último, o texto de Leme e Costa (2016) está fundamentado na Teoria Crítica, de Theodor Adorno. O ensaio teórico é composto por uma análise documental da Declaração Universal dos Direitos Humanos (1948) e da Constituição Federal do Brasil (CF 1988) e uma pesquisa empírica, realizada a partir de um questionário misto para professores de um colégio público, que buscava levantar as percepções e práticas vivenciadas na escola.

A maioria dos textos apresenta estudo de caso e/ou pesquisa empírica, sendo o artigo de Moreira e Carvalho (2014) a única exceção, que não traz dados coletados em campo.

\subsection{Principais resultados/considerações}

Esse tópico apresenta os principais resultados e considerações de cada estudo.

Razuck e Guimarães (2014) notam maior compreensão dos alunos cegos acerca do conteúdo trabalhado, por meio dos relatos do aluno, pelo manuseio do material

elaborado e pelos diálogos com uma das pesquisadoras. É ressaltado, assim, que todos possuem um tempo de aprendizagem diferenciado e a importância da elaboração de recursos pedagógicos. $\mathrm{O}$ estudo considera que a situação de exclusão dos alunos nas escolas está relacionada ao despreparo docente, ocasionado por cursos de formação pouco eficazes. Enfatizam, também, a necessidade de adaptação nas aulas e a importância, no processo de ensino-aprendizagem, do diálogo, de modo que haja espaços para que o aluno verbalize suas percepções.

Razuck e Oliveira Neto (2015) relatam que os kits de modelos moleculares, elaborados sobretudo para estudantes cegos e com baixa visão, sofreram modificações e ajustes a partir de sugestões dos próprios alunos ao entrarem em contato com esses recursos. Estes avaliaram positivamente o material, destacando o modo que permitem uma compreensão melhor do conteúdo. A partir desses modelos, é possível chegar à Grafia Química, instrumento oficial de abordagem representacional no ensino de química 
e pelo qual os discentes se depararão em exames para ingresso no ensino superior. Os autores pressupõem a continuidade de novos métodos e aperfeiçoamento do sugerido, de modo que se possa oportunizar o desenvolvimento do potencial dos alunos e promover o direito cidadão de cada.

Marchi e Silva (2016) atestam que a formação continuada contribuiu para que os professores de química e auxiliares ampliassem, modificassem ou somente aprimorassem de forma crítica o fazer pedagógico. Observou-se, a partir dos depoimentos, que os participantes acreditam na articulação teoria e prática como possibilidade para uma ação mais imediata e concreta, uma vez que as dificuldades podem ser esclarecidas durante o curso. Constatou-se, também, que os docentes perceberam a tecnologia assistiva como recursos que facilitam o aprendizado dos alunos cegos. Os pesquisadores consideram que não há como pensar na efetivação da inclusão sem pensar na formação docente e que é indispensável que os cursos de formação continuada possibilitem a interação entre as dimensões pessoais e profissionais, de modo que a prática seja reflexiva no sentido de fazer modificações que melhorem o desenvolvimento pessoal, profissional e do educando.

Andrade e Freitas (2016) enfocam dois momentos no artigo sobre possibilidades de aprendizagem do aluno cego na Educação Física, o primeiro durante uma aula teórica e outro na prática. Na aula teórica, o estudante não tem acesso ao texto escrito, participando apenas da discussão oral, partilhando suas vivências com os demais alunos e professora, constituindo-se a partir das ações mediadas com o outro, embora fique "barrado" de participação em alguns momentos, quando não tem acesso à escrita no quadro. Durante a aula prática, o estudante participa a partir de orientações faladas e, em alguns momentos, com o auxílio do contato físico. Ele demonstra conhecer todos os seguimentos do próprio corpo e sua participação nesses momentos são possíveis por meios alternativos/compensatórios que a professora encontra para realizar a atividade. $\mathrm{O}$ aluno não é tratado como um corpo marcado pela deficiência, mas sim como alguém com possibilidades de participar e aprender durante as aulas de Educação Física. Os autores enfatizam o papel do outro na aprendizagem do estudante pesquisado, ressaltando a função da linguagem no processo de significação e apropriação dos valores culturais. Destacam que os resultados podem contribuir com reflexões sobre a inclusão escolar e realçam a necessidade de a escola e seus atores atuarem de modo deliberado e intensivo com o intuito de buscarem caminhos e recursos especiais que garantam o acesso de alunos com deficiência ao conhecimento compartilhado na escola. 
Mallmann, Conto, Bagarollo e França (2014) dividem a discussão dos dados coletados nas entrevistas com professores, pedagogos e intérpretes em três eixos: i) Apontamentos positivos/negativos da inclusão, ii) Metodologias de ensino usadas em salas de aula com alunos surdos e iii) A intérprete de LIBRAS na escola regular. No primeiro eixo, todos acreditam na importância da inclusão, mas apontam dificuldades no cotidiano, sobretudo na relação (comunicação) com esses alunos e nas adequações de práticas pedagógicas. Há uma carência de formação profissional e um desconhecimento de que a língua de sinais não é facilitadora, mas sim determinante para o desenvolvimento da pessoa surda. Em relação às metodologias de ensino, os professores relatam que recorrem a outros estudantes na sala para ensinar o conteúdo ao aluno surdo e demonstram na fala que toda a turma forma um grupo homogêneo e o aluno surdo destoa do que é compreendido pela “consciência coletiva”. Nota-se, também, que algumas adaptações nas aulas são individuais e não refletem que a escola esteja voltada para essas questões. $\mathrm{O}$ último eixo incide sobre a importância da intérprete em sala de aula, como profissional que favorece o processo de ensino e aprendizagem. As profissionais demonstram clareza acerca de suas atribuições na interpretação do português falado, atentando que o professor deve assumir a tarefa de adequar o conteúdo. As autoras consideram que uma das dificuldades no processo de inclusão do surdo está relacionada ao não compartilhamento da mesma língua e ao fato de que as escolas regulares não conhecem esse indivíduo. Evidencia-se que tais problemas estão relacionados à defasagem na formação docente para práticas educacionais e que, embora os dados tenham sido coletados no Ensino Médio, os participantes da pesquisa evidenciam preocupações relacionadas apenas a questões de níveis iniciais de escolarização, demonstrando que estas não foram superadas.

Frizzarini e Nogueira (2014), ao analisar as respostas dos alunos surdos, indicam que a LIBRAS tem vantagens em relação às línguas orais, que muitas vezes não são exploradas. Por ser uma língua visual-motora, permite utilizar tanto as unidades visuais do registro gráfico, como as simbólicas, do registro algébrico. É considerado que não se deve separar a representação algébrica dos outros registros devido à necessidade de a língua de sinais desempenhar não apenas a função de comunicação, como também de objetivação e tratamento, fundamentais no desenvolvimento cognitivo. Os autores ressaltam a importância da LIBRAS, que, além de trazer vantagens nas representações algébricas, é a língua natural dos surdos, de modo que as representações mentais destes dependem exclusivamente dela. 
Vargas e Gobara (2014) indicam que as 10 turmas observadas apresentam resultados semelhantes, enfatizando que os professores se mostram preocupados com a aprendizagem do aluno surdo, mas não se esforçavam para tentar concretiza-la, já que não possuíam o hábito de preparar as aulas e nem demonstravam ações que pudessem contribuir para as relações e aprendizagem desse aluno. $\mathrm{O}$ que ficou evidente era que os docentes ministravam aula para a sala toda e em alguns momentos apenas para o estudante surdo, mostrando-se interessados em ensinar, mas limitados devido à falta de conhecimento da LIBRAS. Em relação às interações nos ambientes educacionais, os autores destacam que há uma relação forte com o intérprete, que inclusive não possibilitava que o discente aumentasse o grau de interação com outras pessoas, que não existe uma relação direta entre professor e aluno surdo, apenas tentativas de comunicação por parte dos docentes com o uso da escrita e alguns gestos, e que os alunos ouvintes apenas cumprimentavam os surdos e, normalmente, sentavam afastados destes. Os autores acreditam que as escolas observadas na cidade de Campo Grande (MS) não estão preparadas para receber o estudante surdo, isso porque o ambiente não é adequado e os profissionais não são capacitados para esse fim. Considerando a abordagem teórica adotada (histórico-cultural), eles apontam que nas condições em que o surdo é assistido nas escolas públicas, não há boas oportunidades “[...] para o seu desenvolvimento, pois é por meio das relações sociais que o indivíduo se desenvolve e consegue internalizar o conhecimento favorecendo a aprendizagem" (VARGAS \& GOBARA, 2016, p. 459).

Moreira e Carvalho (2014) verificam que, no período estudado, o maior declive no número de matrícula dos alunos com deficiência foi na permanência no Ensino Fundamental I (Grupo I), que sofreu uma queda de 58,22\% entre 2007 (matrículas $1^{\text {a }}$ série $/ 2^{\circ}$ ano) e 2010 (matrículas $4^{\mathrm{a}}$ série $/ 5^{\circ}$ ano), o que evidencia a descontinuidade logo no primeiro ciclo da educação básica. A esfera que mais contribui para esse fato é a privada, o que indica que os alunos têm evadido ou ficado retido no início do fundamental em escolas especiais. Para as autoras, as políticas de Educação Especial e Ensino Médio, ao longo dos anos, estiveram marcadas de descontinuidades e, apesar de assegurado o direito ao acesso e a transversalidade da Educação Especial em todas as etapas de ensino, os dados analisados mostram que são poucos os alunos que chegam ao Ensino Médio. Por fim, consideram a necessidade de o poder público primar, de fato, pelo direito a essa etapa de ensino para os alunos com deficiência, via elaboração de políticas que articulem a inclusão para além da "inclusão concedida". 
Leme e Costa (2016), inicialmente, analisam o avanço que a Declaração Universal dos Direitos Humanos (1948) e a Constituição Federal (CF/1988) representam nos contextos em que estão situadas, no sentido de trazer à cena a responsabilidade do Estado no que tange à desigualdade social e promoção de oportunidades aos cidadãos. $\mathrm{O}$ princípio de igualdade que consta na $\mathrm{CF} / 1988$ tem como meta, se não acabar, ao menos reduzir as desigualdades econômicas e sociais. Quanto ao estudo empírico presente no ensaio, os pesquisadores indicam que muitos professores trazem palavras que são reveladores da inclusão como direito de todos à educação (tais como participação, respeito, oportunidade e igualdade), reconhecem a diferença e acreditam que deve ser valorizada no cotidiano escolar, mas os dados revelam que as barreiras à participação e aprendizagem dos estudantes são “[...] construídas e mantidas cotidianamente, por serem fruto de nossas concepções, crenças e valores (culturas), pelo modelo de gestão (política) e pelas reações possíveis de cada professor (práticas)" (LEME \& COSTA, 2016, p. 676). Nesse sentido, é posto que a inclusão demanda compromisso por todos em todas as instâncias sociais e a necessidade de imbricamento das dimensões (cultural, política e prática). Os autores partem da premissa de necessidade de se pensar a formação docente, já que as reformas educacionais por si não são suficientes para alcançar os objetivos que se propõem, necessitando do protagonismo do professor, que precisa de formação emancipadora. Consideram que é perceptível certo afastamento desses atores das discussões políticas, o que produz uma lacuna entre o direito afirmado e o direito usufruído, já que os direitos presentes nos documentos na prática se tornam periféricos, e que a ação docente deve estar em consonância com as políticas, não como mera aplicação sem discernimento, mas como ferramenta ciente de seus direitos e deveres.

Percebe-se que cinco entre os nove estudos analisados indicam a defasagem na formação docente e/ou consideram a necessidade de (maior) qualificação desses profissionais, realçando a importância da relação teoria e prática, a (re)avalição das práticas educativas e uma postura política mais participativa do professor.

Os textos que fazem considerações específicas sobre o Ensino Médio são poucos. Dentre esses, Mallmann, Conto, Bagarollo e França (2014) indicam que as preocupações dos profissionais que atuam no Ensino Médio estão mais relacionadas a questões dos anos iniciais do que específicas dessa etapa de ensino, como a alfabetização, e Moreira e Carvalho (2014), que apontam a falta de continuidade nas políticas de Educação Especial e do Ensino Médio, o que acaba contribuindo para o elevado índice de evasão dos alunos com deficiência. 
Apesar de não refletir especificamente sobre o Ensino Médio, é importante considerar que os outros estudos trazem contribuições significativas sobre o ensino e o processo de desenvolvimento e aprendizagem dos alunos em disciplinas específicas (educação física, física, matemática e química), abrindo espaços para a discussão sobre práticas de ensino na diversidade e relações interpessoais em salas de aula "inclusivas".

\section{Tropeçando em pedras, traçando (novos) rumos e alçando voos para o Ensino Médio: considerações sobre obstácullos no caminho}

O levantamento bibliográfico realizado nas revistas de Educação Especial (20142016), permitiu-nos perceber a escassez de estudos específicos sobre o Ensino Médio frente às outras etapas de ensino, já que estes representam apenas 3\% do total dos artigos (276).

Apesar do pequeno número de publicações (nove), identificamos algumas tendências entre as pesquisas divulgadas nos periódicos. Uma delas é que a temática dos textos, grande parte está relacionada ao ensino de disciplinas específicas, sobretudo química para estudantes cegos e com baixa visão (três artigos). Outra questão recorrente é a consideração que a maioria dos textos faz para a necessidade de formação docente, discorrendo que esta seja mais voltada para o conhecimento acerca das características dos alunos "da Educação Especial", às práticas de ensino e à maior participação e engajamento político desses profissionais.

Identificamos, também, a necessidade de estender as pesquisas sobre Ensino Médio e Educação Especial para outras regiões do país, uma vez que a grande concentração de estudos está no sul e sudeste e levando em consideração que cada região tem suas características e necessidades específicas que precisam ser conhecidas e refletidas.

O foco da maioria dos artigos se concentra nas deficiências sensoriais (surdez e cegueira), não havendo estudos sobre os alunos com deficiência intelectual matriculados no Ensino Médio. Isto nos leva a propor que outros estudos possam abordar esse público, uma vez que eles representam a maioria dos alunos "da Educação Especial” matriculados nessa etapa de ensino e suas características também apresentam necessidades especificas para o processo de aprendizagem, por estarem diretamente relacionadas à formação de conceitos científicos, próprios do trabalho da educação escolar. 
A perspectiva teórica explicitada pelos autores é predominantemente a abordagem histórico-cultural. Além dela, há artigos que se fundamentam na dialética marxista, na semiótica e na teoria crítica, todos (de modo geral) demonstrando maior preocupação com as relações sociais vividas no cotidiano escolar e os processos de ensino-aprendizagem. Tanto a perspectiva teórica, quanto os procedimentos metodológicos e as temáticas abordadas nos estudos, não discutem preocupações mais específicas acerca das políticas públicas educacionais relacionadas ao Ensino Médio e à Inclusão Escolar, embora consideremos que as questões abordadas nos estudos realizados são de grande relevância para a área.

A epígrafe que introduz o nosso texto foi retirada de um dos poemas mais conhecidos de Drummond, publicado pela primeira vez em 1928 na Revista Antropofagia, no âmbito do Mordenismo no Brasil. Esse movimento estético-literário foi marcado por experimentações, maior liberdade estética e ruptura com o tradicionalismo, o que influenciou as temáticas tratadas nos poemas e a própria estrutura deles, trazendo temas mais próximos do cotidiano, tidos muitas vezes como "banais". Um dos possíveis, e principais, sentidos atribuídos para os escritos do poeta moderno pode estar relacionado com os obstáculos encontrados no caminho (vida), que muitas vezes anulam as possibilidades de seguir, de agir, de fazer.

Hoje, há uma série de pedras no(s) caminho(s) entre a (transversalidade da) Educação Especial/Inclusiva e as etapas mais avançadas de ensino; pedras que talvez pudessem ser mais encaradas, discutidas e pesquisadas. Sabe-se que, apesar do direito ao acesso à educação regular ser um crescente a cada ano, os dados do próprio Censo, quando analisados, indicam que existem dificuldades relacionadas à permanência desse alunado na escola.

Em larga escala, é óbvio que o debate sobre o Ensino Médio e a atual reforma não engloba somente (o interesse e) a figura do jovem, mas, e sobretudo, os interesses políticos, sociais e, cada vez mais, os empresariais e comerciais. Em uma sociedade marcada pela divisão de classes e exclusão socioeconômica e cultural como no Brasil, a habilitação técnica prevista entre os cinco itinerários soa sedutora para os estudantes socioeconomicamente desfavorecidos, que projetarão nesse tipo de itinerário um modo de ascender socialmente, como também uma forma mais rápida para trabalhar e auxiliar nas despesas. 
Nesse contexto, é muito importante alguns questionamentos: as atuais pesquisas no âmbito acadêmico tem se restringido apenas à observação e identificação ou, também, como suporte para transform(ações)? De que modo a academia pode responder às (novas) reformas no Ensino Médio e lutar por um ensino público de qualidade e uma sociedade mais justa, com menor exploração, menor acúmulo de renda e maior respeito às diversidades?

As respostas a essas questões são complexas, mas a problematização é necessária.

Os caminhos trilhados pelo Ensino Médio e pelo movimento de inclusão nas escolas regulares brasileiras, sem dúvida, ainda são nebulosos, extensos e recheados de pedras. Esperamos, a partir da exposição de alguns estudos e breves considerações, ter provocado e chamado o leitor para alguns problemas relacionados à essa etapa de ensino e a permanência do alunado da Educação Especial no ensino regular, levando em consideração que há muitos pontos ainda que devem ser discutidos. Nos estudos analisados, por exemplo, apenas um deles (MARCHI; SILVA, 2016) discorre brevemente - sobre o trabalho do professor regular com o docente do Atendimento Educacional Especializado, que hoje é o serviço primordial na complementação/suplementação dos estudantes da Educação Especial. Cabe aqui, também, uma gama de questionamentos, tais como: de que modo o profissional do AEE atua no Ensino Médio? E, com a implementação das atuais reformas, que dinâmicas serão utilizadas para o atendimento dos diferentes alunos nas escolas públicas? Atentando-se para o fato, nessa última questão, de que a maioria das escolas oferecerá provavelmente apenas um itinerário e que a maioria delas tem apenas uma sala de recursos, "especializada" apenas em um tipo de necessidade especial (cegueira, surdez, deficiência intelectual, etc.).

Para encerrar esse diálogo, pedimos licença ao leitor para prosseguir com alguns usos figurados, tendo agora por objetivo ampliar nossa conversa, propondo uma breve reflexão acerca da educação escolar e a situação atual que vivemos, marcada pela intensificação da luta de classes, corrupção e progressiva queda dos direitos conquistados pela classe trabalhadora. É necessário tropeçar para incomodar, é necessário tropeçar para problematizar, é necessário tropeçar para prosseguir, é necessário tropeçar para buscar diferentes direções e alçar voos. Nesse caminho, onde as pedras se colocam e se revestem de diferentes sentidos, estão o aluno, o professor, a educação escolar e os sentidos dessa prática (no Ensino Médio) em nosso país. Afinal, ensinar para se conformar ou ensinar para tropeçar? 


\section{REFERÊNCIAS BIBLIOGRÁFICAS}

ANDRADE, J. M. A.; FREITAS, A. P. de. Possibilidades de aprendizagem de um aluno com cegueira no contexto da Educação Física escolar. Revista Educação Especial, Santa Maria, v. 29, n. 56, p. 737-750, set./dez. 2016

\section{BRASIL. Política Nacional de Educação Especial na Perspectiva da Educação}

Inclusiva. Brasília: MEC/SEESP, 2008. Disponível em:

$<$ http://portal.mec.gov.br/index.php?option=com_docman\&view=download\&alias=166

90-politica-nacional-de-educacao-especial-na-perspectiva-da-educacao-inclusiva-

05122014\&Itemid=30192> . Acesso em: 12 mai. 2017.

Lei no 13.005, de 25/06/2014. Aprova o Plano Nacional de Educação. Diário Oficial da União, Brasília, DF, 26 jun. 2014. Disponível em:

<http://www.observatoriodopne.org.br/uploads/reference/file/439/documento-

referencia.pdf $>$. Acesso em: 12 mai. 2017.

FRIZZARINI, S. T.; NOGUEIRA, C. M. I. Conhecimentos prévios dos alunos surdos fluentes em libras referentes à linguagem algébrica no Ensino Médio. Revista

Educação Especial, Santa Maria, v. 27, n. 49, p. 373-390, maio/ago. 2014.

LAPLANE, A. L. F. de. Condições para o ingresso e permanência de alunos com deficiência na escola. Caderno Cedes, Campinas, v. 34, n. 93, p. 191-205, maio/ago. 2014.

de. Trajetórias escolas e deficiência: reflexões sobre os dados do

Censo Escolar. In: VICTOR, S. L.; OLIVEIRA, I. M. de. (orgs.). Educação Especial: Políticas e formação de professores. Marília: ABPEE, 2016, p. 35 - 45.

LEMOS, E. S.; COSTA, V. A. da. Educação, inclusão e direitos humanos: como esse estuário desaguou na escola? Revista Educação Especial, v. 29, n. 56, p. 667-680, set./dez. 2016.

LIMA, S. M.; LAPLANE, A. L. F. de. Escolarização de alunos com autismo. Revista Brasileira de Educação Especial, Marília, v. 22, n. 2, p. 269-284, abr./jun. 2016.

MALLMANN, F. M.; CONTO, J. de.; BAGAROLLO, M. F. ; FRANCA, D. M. V. R. A inclusão do aluno surdo no Ensino Médio e Ensino Profissionalizante: um olhar para o discurso dos educadores. Revista Brasileira de Educação Especial, Marília, v. 20, n. 1, p. 131-146, jan./mar. 2014.

MARCHI, M. I.; SILVA, T. N. da C. Formação continuada de professores: buscando melhorar e facilitar o ensino para deficientes visuais por meio de tecnologias assistivas. Revista Educação Especial, Santa Maria, v. 29, n. 55, p. 457-470, maio/ago. 2016.

MELETTI, S. M. F.; RIBEIRO, K. Indicadores educacionais sobre a educação especial no Brasil. Caderno Cedes, Campinas, v. 34, n. 93, p. 175-189, maio/ago. 2014. 
MOREIRA, L. C.; CARVALHO, A. P. de. (Des)continuidade nos estudos de alunos com deficiência na trajetória do Ensino Fundamental ao Médio: uma análise inicial dos microdados MEC/INEP. Revista Educação Especial, Santa Maria, v. 27, n. 49, p. $283-$ 298, maio/ago. 2014.

RAZUCK, R. C. de S. R.; GUIMARÃES, L. B. O desafio de ensinar modelos atômicos a alunos cegos e o processo de formação de professores. Revista Educação Especial, Santa Maria, v. 27, n. 48, p. 141-154, jan./abr. 2014

RAZUCK, R. C. de S. R.; OLIVEIRA NETO, W. de. A química orgânica acessibilizada por meio de kits de modelo molecular adaptados. Revista Educação Especial, Santa Maria, v. 28, n. 52, p. 473-486, maio/ago. 2015

VARGAS, J. S.; GOBARA, S. T. Interações entre o aluno com surdez, o professor e o intérprete em aulas de Física: uma perspectiva Vygotskiana. Revista Brasileira de Educação Especial, Marília, v. 20, n. 3, p. 449-460, jul./set. 2014.

Recebido em: 13/09/1017

Aceito em: 04/10/2017 